\title{
Editorial
}

\section{Mathematical and Numerical Modeling in Geotechnical Engineering}

\author{
Ga Zhang, ${ }^{1}$ Pengcheng Fu, ${ }^{2}$ and Fayun Liang ${ }^{3}$ \\ ${ }^{1}$ School of Civil Engineering, Tsinghua University, Beijing 100084, China \\ ${ }^{2}$ Atmospheric, Earth, and Energy Division, Lawrence Livermore National Laboratory, Livermore, CA 94550, USA \\ ${ }^{3}$ Department of Geotechnical Engineering, College of Civil Engineering, Tongji University, Shanghai 200092, China
}

Correspondence should be addressed to Ga Zhang; zhangga@tsinghua.edu.cn

Received 2 October 2013; Accepted 2 October 2013

Copyright (c) $2013 \mathrm{Ga}$ Zhang et al. This is an open access article distributed under the Creative Commons Attribution License, which permits unrestricted use, distribution, and reproduction in any medium, provided the original work is properly cited.

Mathematical and numerical modeling is a mature yet vibrant research area in geotechnical engineering. Its advancement has been accelerated in recent years by many emerging computational techniques as well as the increasing availability of computational power. A wide spectrum of approaches, on the basis of continuously advancing understanding of soil behavior, has been developed and applied to solve various problems in geotechnical engineering. These methods are increasingly playing important roles not only in achieving better understanding of fundamental behavior of geomaterials and geostructures but also in ensuring the safety and sustainability of large-scale complex geoengineering projects.

The aim of this special issue is to present original research articles on mathematical and numerical modeling in geotechnical engineering. A total of 26 high-quality peerreviewed papers were selected to be published in this special issue. The topics cover various aspects as follows.

(1) Development and discussion of constitutive models of geomaterials including unsaturated soil, granular, rockfill, joint rock mass, and soil-structure interface.

(2) Proposal of analytical solutions to soil-structure interaction systems.

(3) Development of numerical methods to evaluate response of retaining wall, pile foundation.

(4) Novel applications of mathematical and numerical modeling to practical geotechnical projects such as pile foundations, soil nails, mining, joint rock mass, rock grouting, rockfill dams, and arc dams.
These papers are expected to be helpful references for all those in the field of mathematical and numerical modeling in geotechnical engineering.

\section{Acknowledgments}

The guest editors of this special issue would express their sincere gratitude to all the authors and anonymous reviewers who have generously contributed to this special issue.

Ga Zhang

Pengcheng Fu

Fayun Liang 


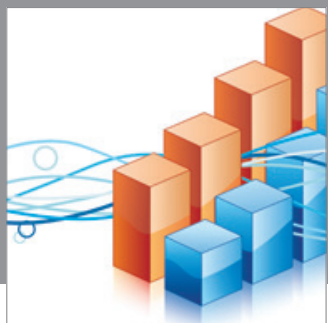

Advances in

Operations Research

mansans

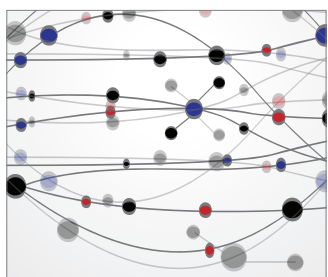

The Scientific World Journal
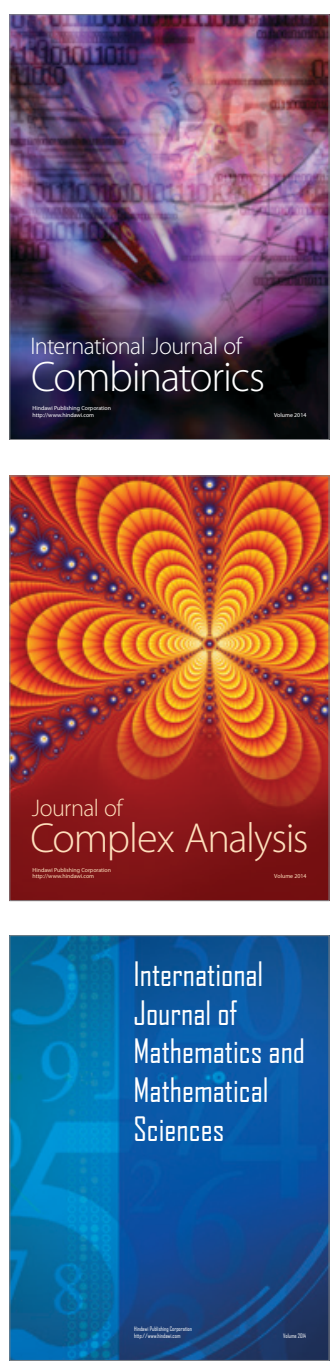
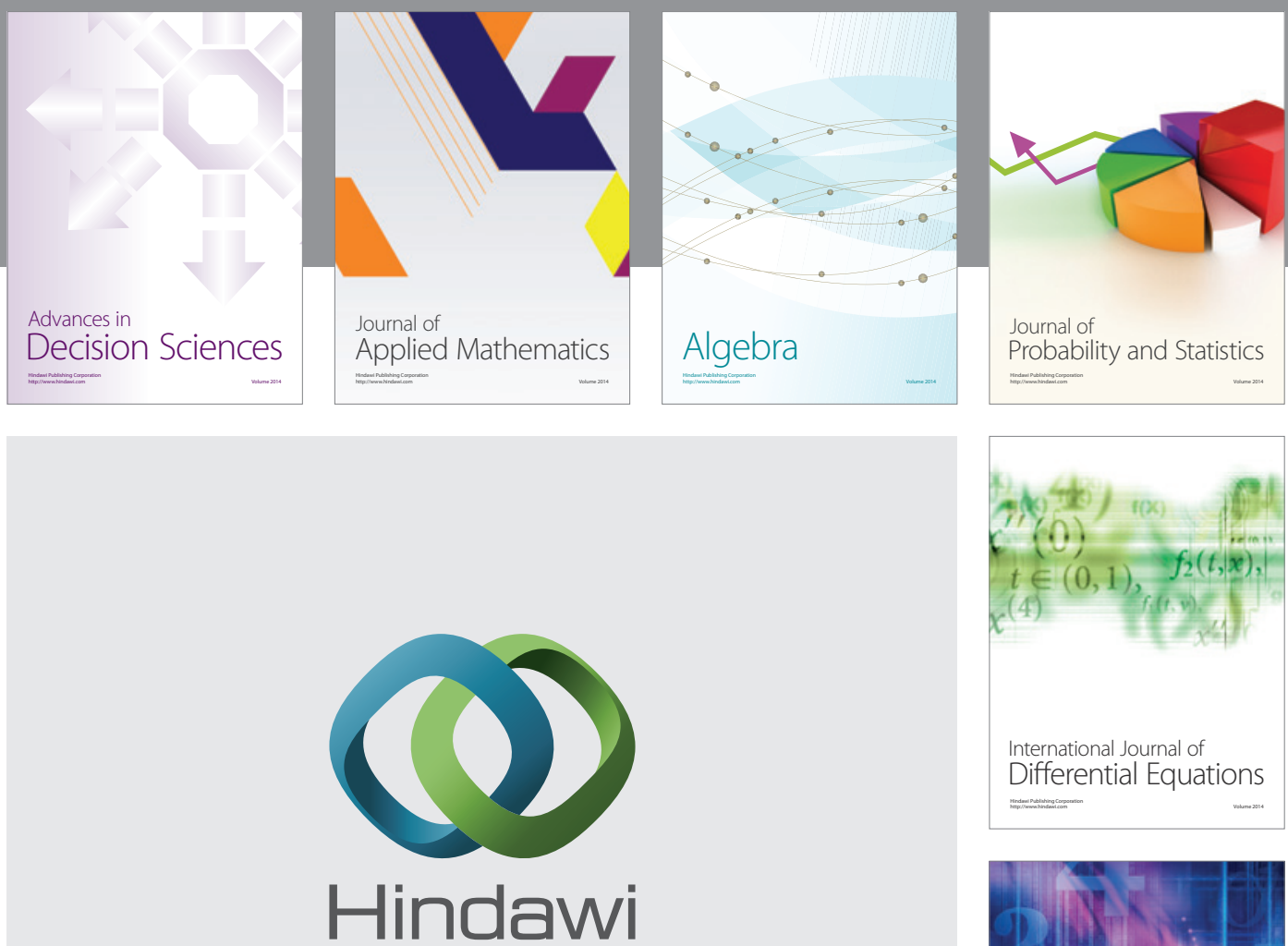

Submit your manuscripts at http://www.hindawi.com
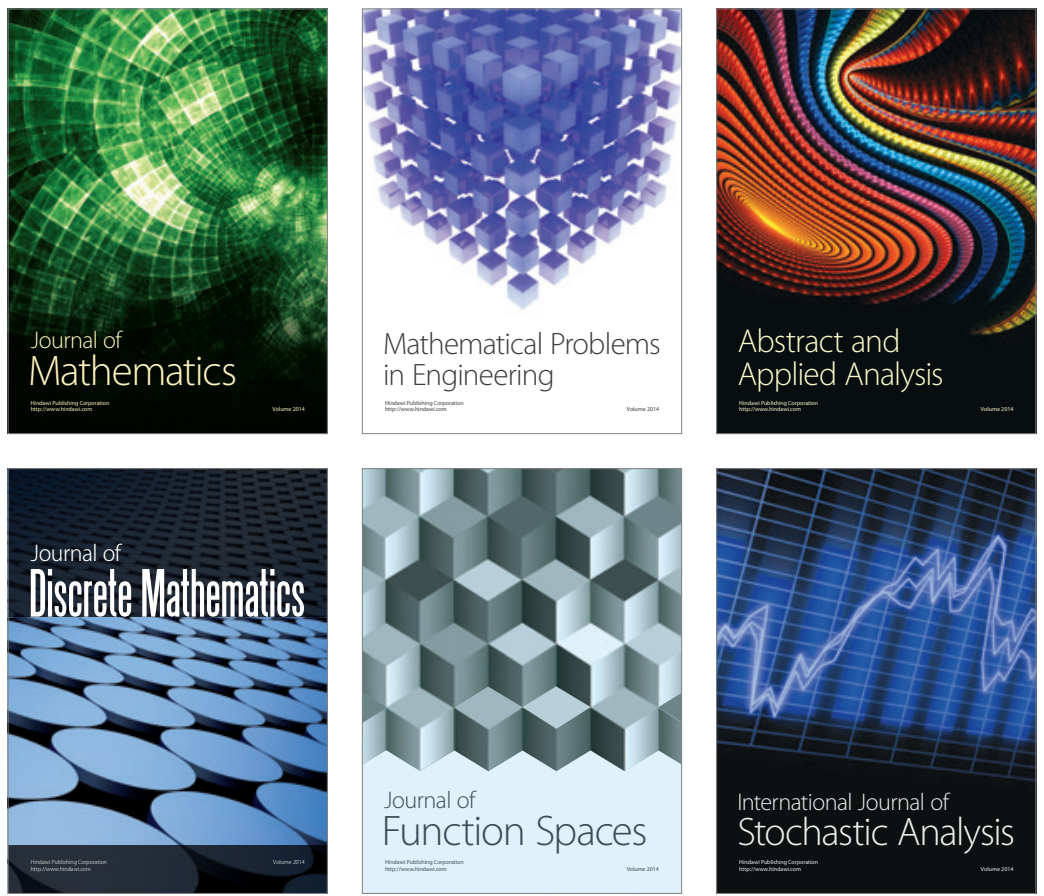

Journal of

Function Spaces

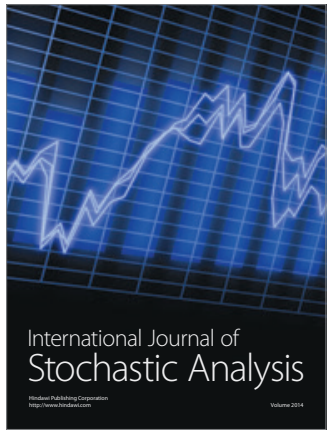

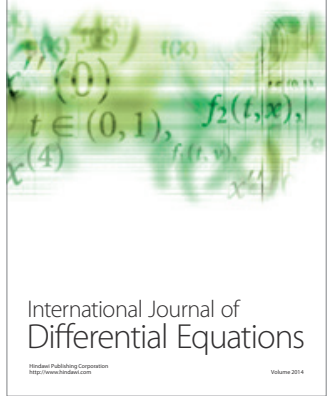
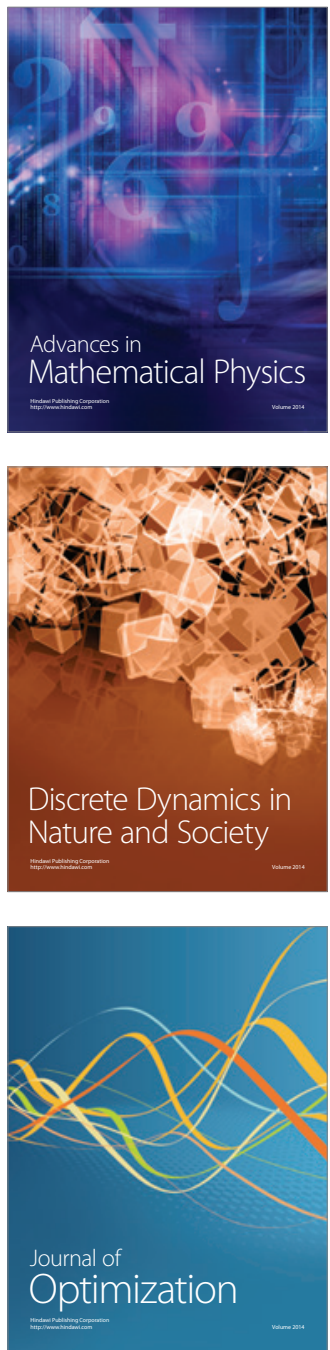